\title{
IMPLEMENTAÇÃO DE COMPOSTEIRAS E HORTAS ORGÂNICAS EM ESCOLAS: SUSTENTABILIDADE E ALIMENTAÇÃO SAUDÁVEL
}

\author{
Mariana Guenther $^{1}$ \\ Juliana de Melo Souza² \\ Eduardo Enrique Barbosa Carvalho² \\ Gabriel Amorim de Almeida Arruda ${ }^{2}$ \\ Artur Torquato Pereira de Souza ${ }^{2}$ \\ Rafaella Kelynne de Medeiros Pereira ${ }^{2}$ \\ Thays Maria Queiroz Abreu² \\ Laís Araújo da Silva²
}

Resumo: Nesse artigo relatamos os resultados de um projeto de extensão universitária realizado junto às comunidades escolares do estado de Pernambuco (NE Brasil), onde ensinamos alunos e professores a construir composteiras utilizando materiais reutilizáveis, e a utilizar o adubo gerado em hortas orgânicas implementadas na própria escola. Durante o processo, discutimos a importância da alimentação saudável, a viabilidade da produção orgânica, os perigos da utilização de agrotóxicos para a saúde e para o ambiente, o reaproveitamento eficiente dos resíduos através da compostagem, além dos processos físicos, químicos e biológicos envolvidos na decomposição desses resíduos.

Palavras-chave: Compostagem; Alimentação Orgânica; Educação Ambiental; Gestão de Resíduos.

\footnotetext{
1 Doutora em Ciências - Oceanografia Biológica pela Universidade de São Paulo - USP, Professora Adjunta do Instituto de Ciências Biológicas da Universidade de Pernambuco - UPE. E-mail: mariana.guenther@upe.br

2 Graduando(a) em Ciências Biológicas pela Universidade de Pernambuco.
} 
Abstract: We report in this paper a university outreach project carried out with school communities of the state of Pernambuco, NE Brazil, where we taught students and teachers how to build composters using reused materials and to use the prepared fertilizer in organic gardens implemented in the school. During the process, we discussed the importance of healthy eating, the viability of organic production, the dangers of using pesticides for health and environment, the efficient reuse of waste through composting, as well as the physical, chemical and biological processes involved in decomposition of these wastes.

Keywords: Composting; Organic Food; Environmental Education; Waste Management.

\section{Introdução}

O cultivo de alimentos em larga escala necessita da aplicação de grandes quantidades de defensivos agrícolas e fertilizantes. A utilização de agrotóxicos no Brasil é um problema crescente, levando à contaminação dos solos, das águas e dos alimentos que serão consumidos por todos nós. Muitos produtos proibidos na maioria dos países têm livre acesso no Brasil devido a uma legislação permissiva e fiscalização inexistente (LONDRES, 2011).

Grande parte da produção agrícola mundial é desperdiçada seja durante o transporte, seja nas feiras e prateleiras dos supermercados devido ao alto preço, dificultando o acesso a alimentos saudáveis por grande parte da população. O problema da fome no mundo está muito mais relacionado ao desperdício de alimentos do que sua escassez (NELLEMANN et al., 2009). Além disso, o alto grau de desperdício contribui para a maior geração e acúmulo de resíduos no planeta.

Problemas alimentares como a obesidade e a desnutrição vêm atingindo uma fração cada vez maior da população mundial, principalmente crianças (MIKKILÄ et al., 2007; NCD, 2017). A qualidade da alimentação da criança depende de vários fatores econômicos, geográficos, sociais e culturais. Em relação ao consumo de vegetais, este vai variar dependendo da oferta local e da estação do ano, mas também do poder aquisitivo da família e dos seus hábitos e costumes (ROSSI et al., 2008). Uma reeducação alimentar aliada a um maior acesso a alimentos saudáveis são, portanto, metas urgentes a serem atingidas.

O ambiente escolar é ideal para a formação de cidadãos mais conscientes quanto aos problemas sociais, econômicos e ambientais que nos cercam. Nele há a possibilidade de apropriações de saberes, debates e discussões e construção de conhecimento. Nesse ambiente, cultivar hábitos mais saudáveis e sustentáveis se torna imperativo, pois daí surgirão cidadãos transformadores do seu meio.

Dentro desse contexto, nosso objetivo foi promover um enriquecimento do ambiente escolar, capacitando alunos, professores e funcionários para a produção de hortaliças em espaços limitados utilizando o produto da 
compostagem como fertilizante natural, enquanto discutimos a importância da alimentação saudável, do cultivo orgânico de alimentos e da redução dos resíduos, e aprofundamos os conteúdos escolares, trabalhando-os de forma prática, transversal e integrada.

Através da implantação de sistemas de compostagem e hortas orgânicas em escolas do estado de Pernambuco, região nordeste do Brasil, trabalhamos vários temas em conjunto, tais como: o uso da terra para plantio (preparação, adubação, semeadura e irrigação) e a decomposição da matéria orgânica utilizando os conteúdos escolares relacionados; a importância de uma alimentação mais saudável, orgânica e livre de agrotóxicos, para a saúde e para o ambiente; a redução da geração de resíduos através da reutilização de restos de alimentos para a compostagem; e a reutilização de materiais não orgânicos para a construção das hortas, como resíduos plásticos e metais.

Todo esse processo tem um efeito multiplicador incontestável, desde a transmissão das técnicas aprendidas para sua comunidade, amigos e familiares até a possibilidade de, através da sensibilização adquirida, influenciar mudança de hábitos alimentares e de consumo.

\section{Agricultura orgânica $X$ agrotóxicos}

A monocultura, ou seja, o cultivo de uma espécie vegetal em larga escala, extingue rapidamente os nutrientes do solo sendo necessária a adição de fertilizantes. Por se tratar de áreas extensas, a utilização de fertilizantes sintéticos se faz economicamente mais viável do que o adubo orgânico, embora mais perigoso para a saúde e para o ambiente (NEVES et al., 2006).

Além da necessidade de fertilizantes, a monocultura estimula 0 crescimento populacional de algumas espécies de insetos herbívoros, além de fungos, denominados, portanto, de "pragas" ou "pestes" por terem o potencial de consumir grande parte da produção. Em uma floresta natural, há uma diversidade de herbívoros que se alimenta da diversidade existente de plantas a uma taxa baixa, que não compromete a produção florestal. Assim, a monocultura necessita do que chamamos de defensivos agrícolas ou "pesticidas" para o controle desses animais e fungos, que em sua grande maioria é feito através da utilização de substâncias altamente tóxicas e prejudiciais à saúde e ao ambiente, os chamados "agrotóxicos" (PERES; MOREIRA, 2003).

O uso intensivo de agrotóxicos em escala mundial teve início após a Segunda Guerra Mundial impulsionado pelas indústrias envolvidas na fabricação de armas químicas durante a guerra. Uma série de políticas lideradas pela FAO (Food and Agriculture Organization of the United Nations Organização das Nações Unidas voltada para a Alimentação e Agricultura) e pelo Banco Mundial foram então desenvolvidas com o intuito de expandir o mercado agrícola mundial e assim combater a fome que assolava a população 
nesse período pós guerra, a chamada "Revolução Verde" (MOREIRA, 2000; ALBERGONI; PELAEZ, 2007; ANDRADES; GANIMI, 2007).

No Brasil, o uso de agrotóxicos se desenvolveu na década de 60 , com a criação do Sistema Nacional de Crédito Rural, em 1965, que obrigava aos agricultores a aquisição de insumo químicos para a obtenção de crédito (FÜRSTENAU, 1987; BANCO do BRASIL, 2004) e o Programa Nacional de Defensivos Agrícolas, criado em 1975, que facilitou, entre outros, a instalação de empresas produtoras desses insumos (BULL; HATHAWAY, 1986; LONDRES, 2011). A partir dos anos 90, é possível observar um aumento brusco no consumo de agrotóxicos no Brasil, diretamente relacionado ao aumento de casos de intoxicação por essas substâncias (PORTO; SOARES, 2012).

Uma alternativa mais saudável e sustentável à monocultura em larga escala são os sistemas agroflorestais (SAFs). Nesses sistemas, as espécies cultivadas são plantadas juntamente a plantas lenhosas perenes (muitas vezes são árvores frutíferas), atraindo uma maior diversidade de polinizadores e dispersores e criando assim um ecossistema de relações mais complexas (LUNDGREN; RAINTREE, 1982; CANUTO, 2017). Assim, a alternância de culturas permite o retorno dos nutrientes ao solo, de modo que não seja necessária a adição de fertilizantes. A adubação é feita através da compostagem do material oriundo do próprio sistema (resíduos vegetais como galhos, folhas, flores, frutos) e a diversidade vegetal dificulta o estabelecimento de pragas.

\section{O desperdício de alimentos e a geração de resíduos}

O desperdício de alimentos e a má gestão da produção é uma das maiores causas da fome no nosso país e no mundo (NELLEMANN et al., 2009). É comum observarmos frutas e verduras se estragando nas prateleiras dos mercados ao invés de serem distribuídas à população de baixa renda que não possui meios de adquirir tais alimentos. Para a lógica do mercado, é mais válido descartar os alimentos do que vendê-los a um preço menor ou mesmo doá-los ao fim do dia, quando estes não poderão ser mais comercializados. Como resultado, toneladas de resíduos orgânicos são geradas todos os dias, sendo geralmente descartadas juntamente com resíduos sólidos de todos os tipos, dificultando sua seleção e destinação corretas (BELIK et al., 2012).

Mesmo se assumíssemos uma taxa mínima de desperdício de alimentos tanto nos mercados quanto nos restaurantes, lanchonetes e outros estabelecimentos gastronômicos, ainda teríamos uma grande quantidade de resíduos orgânicos como cascas e sementes de frutas e legumes além de restos de verduras que são descartados diariamente (MARCHETTO et al., 2008; LEMOS et al., 2011). A utilização de resíduos orgânicos para a produção de adubo em sistemas de compostagem é uma técnica milenar, utilizada em 
várias culturas (KIEHL, 1985) e bastante difundida nos setores agrícola e industrial ao redor do mundo (OLIVEIRA et al., 2004; BARREIRA et al., 2006).

A compostagem dos resíduos orgânicos traz uma série de vantagens ambientais em relação à sua deposição em aterros sanitários, como a diminuição do volume de resíduos nos aterros, a redução da emissão de gases, como o metano, e a redução da eutrofização causada pela lixiviação do chorume para os corpos d'água (LOU; NAIR, 2009; RUGGIERI et al., 2009; TAIWO, 2011), e tem sido cada vez mais utilizada como uma opção economicamente rentável, além de sustentável (EGGERTH et al., 2007; RAZZA et al., 2018).

Atualmente, sistemas de compostagem têm sido também utilizados em escalas menores pelas populações urbanas, em suas casas e apartamentos, como forma de reduzir a quantidade de resíduo gerado e de aproveitar o adubo produzido em pequenas hortas cultivadas para consumo próprio (BECK-FRIIS et al., 2000; SMÅRS et al., 2002; NEUGEBAUER; SOŁOWIEJ, 2017).

\section{A alimentação saudável começa na infância}

A alimentação inadequada é a principal causa dos altos índices de sobrepeso e obesidade observados em escala mundial que têm reflexo direto no aumento de casos de doenças cardiovasculares, principal causa de morte no Brasil e no mundo (MALACHIAS et al., 2016). Um estudo recente baseado em dados da Organização Mundial da Saúde demonstrou um aumento considerável nos índices de obesidade em crianças e adolescentes entre $05 \mathrm{e}$ 19 anos (NCD, 2017). Comparações entre os anos de 1975 e 2016 mostraram um aumento global nos índices de obesidade tanto em meninos (de 0,9\% da população mundial nesta faixa etária em 1975 a 7,8\% em 2016) quanto em meninas (de $0,7 \%$ da população mundial nesta faixa etária em 1975 a 5,6\% em 2016). Ao mesmo tempo os índices de crianças moderadamente ou severamente abaixo do peso, ou seja, os índices de desnutrição moderada a severa baixaram de 9,2\% da população mundial nesta faixa etária em 1975 a $8,4 \%$ em 2016 para as meninas e de $14,8 \%$ da população mundial nesta faixa etária em 1975 a 12,4 \% em 2016 para os meninos. Em números populacionais totais, para essa faixa etária de 05 a 19 anos, temos para o ano de 2016 uma estimativa de 75 milhões de meninas e 117 milhões de meninos em situação de desnutrição moderada a severa e 50 milhões de meninas e 74 milhões de meninos obesos. A tendência é que em poucos anos o número de crianças e adolescentes obesos superem aquele de crianças e adolescentes com desnutrição moderada a severa.

O aumento de índices de obesidade na população mundial está intimamente relacionado ao aumento das cadeias de fast-foods nas últimas décadas que oferecem alimentos ultra processados ricos em açúcares e gorduras trans (ASTRUP et al., 2008). Tais alimentos, também encontrados em grande quantidade e variedade nos supermercados fornecem uma refeição 
rápida e prática (já estão prontos ou são congelados e rapidamente aquecidos em fornos de micro-ondas) e mais econômica. O custo da refeição industrializada do tipo fast-food é muito inferior quando comparado a uma refeição natural e balanceada, o que dificulta ainda mais a procura por uma alimentação saudável por grande parte da população (POPKIN et al., 2012).

No Brasil, uma pesquisa realizada pelo Instituto Brasileiro de Geografia e Estatística (IBGE) entre os anos de 2008 e 2009 sobre o consumo de alimentos entre adolescentes, adultos e idosos, demonstrou alto consumo de alimentos ultra processados como refrescos, refrigerantes, bebidas lácteas, biscoitos industrializados e salgadinhos, principalmente entre adolescentes (IBGE, 2010). Menos de $10 \%$ da população atingiu as recomendações de consumo de alimentos frescos como frutas, verduras e legumes, e o consumo de leite e derivados também está muito abaixo do recomendado. Em média, considerando todas as regiões do Brasil, o consumo de alimentos fora do domicílio equivale a $40 \%$ do consumo diário, o que contribui também para esse desequilíbrio na alimentação. O resultado desse padrão alimentar observado nos brasileiros, principalmente entre os adolescentes, é uma alta ingestão de açúcares, gorduras saturadas e sódio, muito acima dos valores recomendados, e uma ingestão deficitária de vitaminas, fibras alimentares e cálcio.

Entre as crianças, os hábitos alimentares também são preocupantes. Um estudo realizado com 719 estudantes de escolas públicas do estado do Rio Grande do Sul, região Sul do Brasil, na faixa de 05 a 19 anos, demonstrou que apenas $22,0 \%(n=139)$ apresentou alto consumo de alimentos saudáveis (saladas, legumes e verduras cozidos; frutas; feijão; leite/iogurte) e baixo consumo de alimentos não saudáveis (alimentos fritos; hambúrguer e embutidos; biscoitos salgados ou salgadinhos; bolachas, balas, doces e chocolates; e refrigerantes). Separando o grupo entre crianças (05 a 09 anos) e adolescentes (10 a 19 anos), esse mesmo estudo demonstrou que as crianças possuíam um hábito alimentar mais saudável do que os adolescentes (CORRÊA et al., 2017). Esse padrão também foi observado em outros países como os EUA, Austrália e Inglaterra (GOLLEY et al., 2011; FUNGWE et al., 2005; NORTHSTONE et al., 2012).

Durante a primeira infância, a alimentação é determinada principalmente pelos pais ou cuidadores da criança. Quando esta entra na fase escolar, entram em cena outros responsáveis, e a escola adquire um papel fundamental seja na manutenção de hábitos saudáveis já cultivados em casa, seja na construção de novas práticas alimentares. As mudanças no comportamento alimentar do adolescente se devem tanto às mudanças fisiológicas quanto à maior influência do seu meio social (COSTA et al., 2001; MIKKILÄ et al., 2007; ROSSI et al., 2008). Por isso, o trabalho de base é tão importante e a escola passa a ser uma forte aliada aos cuidadores das crianças nesse processo. 


\section{As instituições de ensino participantes desse projeto}

Esse projeto foi desenvolvido em três escolas públicas localizadas na região metropolitana do Recife e arredores, no estado de Pernambuco, Brasil: Escola Estadual Professora Inalda Spinelli (EEPIS), localizada no bairro de Boa Viagem, município de Recife; Escola Estadual Professor Benedito Cunha Melo (EEPBCM), localizada no bairro de Barra de Jangada, município de Jaboatão dos Guararapes; Escola Municipal Padre Miguel (EMPM), localizada no bairro de Tabatinga, município de Camaragibe (Figura 1).

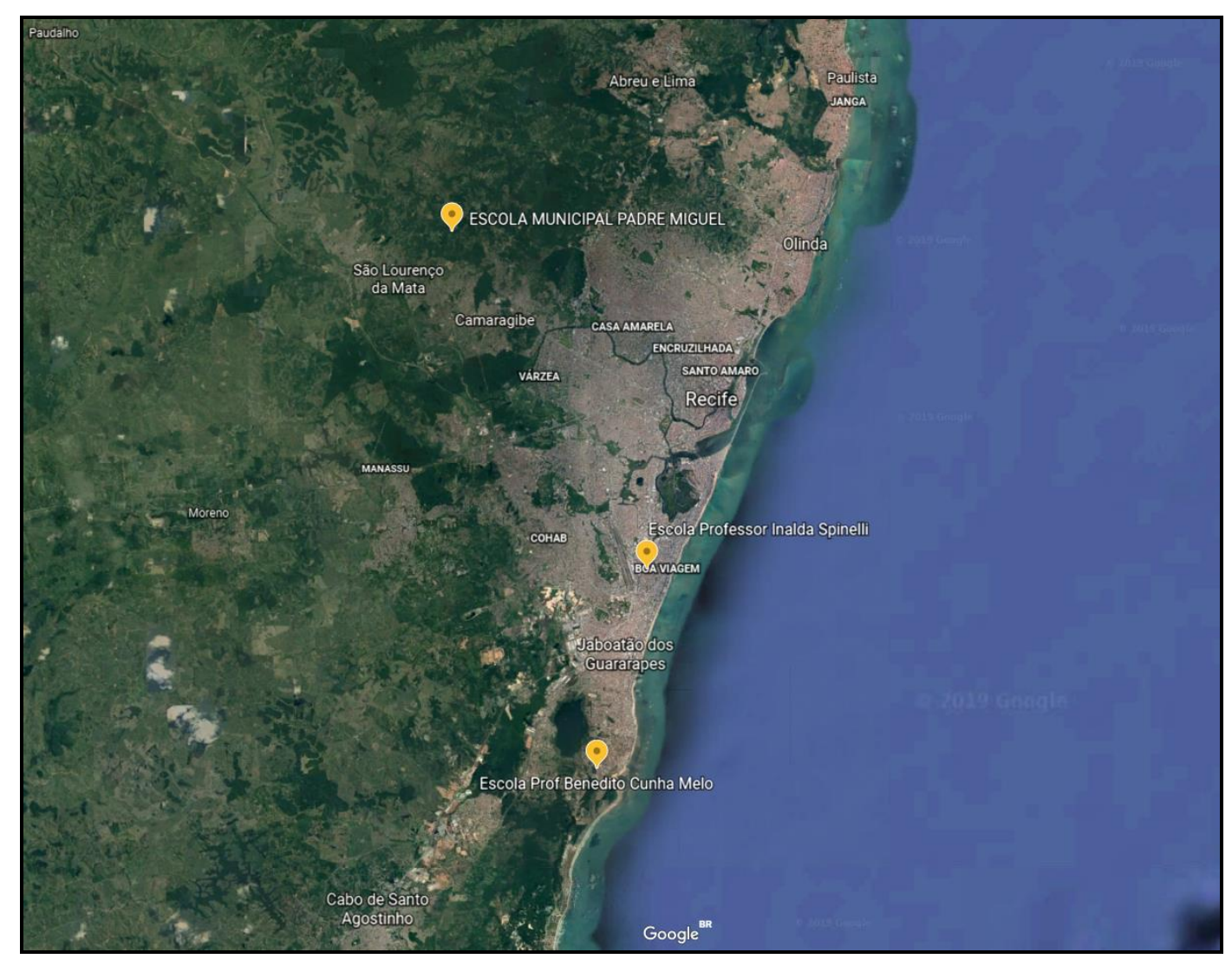

Figura 1: Localização das escolas participantes desse projeto

Fonte: Google Earth.

Os alunos participantes, cursando desde o Ensino Fundamental I até o Ensino Médio, apresentaram faixa etária variando de 08 a 18 anos. Para cada escola, as atividades foram realizadas para um grupo etário específico, pois a linguagem e a abordagem utilizadas variaram de acordo com a idade do público. Essas escolas foram escolhidas por apresentarem tanto uma diversidade etária, incluindo o Ensino Fundamental I, II e Médio, quanto espacial e estrutural, ocupando tanto áreas urbanas quanto a área rural, o que promoveu um enriquecimento maior das atividades e dos debates com os alunos (Tabela 1). 
Tabela 1: Características das diferentes escolas participantes.

\begin{tabular}{llll}
\hline & EEPIS & EEPBCM & EMPM \\
\hline Município & Recife & Jaboatão & Camaragibe \\
Zona & Urbana & Urbana & Rural \\
Nível & Fund. II e Médio & Ensino Médio & Fundamental I \\
No Funcionários & 67 & 77 & 24 \\
No Alunos & 824 & 437 & 116 \\
Área externa & Não & Sim & Sim \\
Cozinha & Sim & Sim & Sim \\
\hline
\end{tabular}

Fonte: Secretaria de Educação e Esportes do Estado de Pernambuco.

As escolas participantes possuem diferentes arranjos estruturais e, portanto, possibilidades variadas de implantação das hortas e composteiras. $\mathrm{Na}$ primeira visita às escolas, quando apresentamos o projeto aos diretores, já avaliamos os espaços e as possibilidades de trabalho em cada um. Enquanto a EEPBCM (localizada no município de Jaboatão dos Guararapes) e a EMPM (localizada no município de Camaragibe) apresentavam espaço para cultivo de hortaliças já bem desenvolvido, a EEPIS (localizada no município de Recife) não possuía espaço físico para a implantação da horta no modelo clássico "horizontal", tendo esta que ser readaptada ao modelo "vertical".

Para cada escola, seguimos um protocolo semelhante, que se iniciou com uma roda de conversa para depois seguirmos com a construção dos sistemas de compostagem e a implantação ou manutenção das hortas.

\section{Roda de conversa: infância e alimentação saudável}

O primeiro contato com os alunos, após a apresentação da proposta aos diretores e professores das escolas, se deu através de palestras expositivas e rodas de conversas informais, que tiveram como objetivo sensibilizá-los quanto à importância da alimentação saudável, quanto aos benefícios e viabilidade econômica da produção orgânica, quanto aos danos causados à saúde e ao ambiente pela utilização dos agrotóxicos, quanto à possibilidade de reaproveitamento dos restos alimentares através da compostagem e quanto aos problemas causados pelo acúmulo de resíduos não orgânicos no ambiente, como os plásticos, e a importância da reutilização desses materiais. Apesar da profundidade dos temas discutidos, esse momento se deu de forma bastante informal com todos os grupos trabalhados, possibilitando aos alunos se expressar de maneira espontânea. As respostas dos alunos foram registradas por escrito para posterior análise e discussão (Figura 2). 


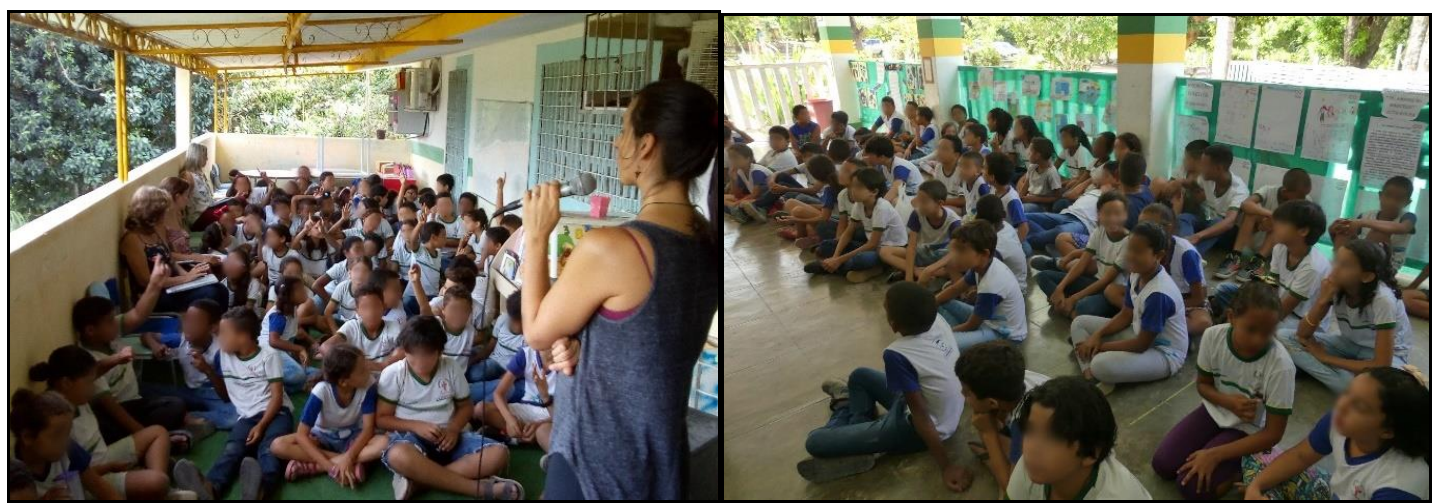

Figura 2: Rodas de conversas nas escolas: apresentação do projeto e discussão dos temas

Fonte: os autores.

A qualidade da alimentação da criança depende de vários fatores econômicos, geográficos, sociais e culturais. Os vegetais consumidos vão variar dependendo da oferta local e da estação do ano, mas também do poder aquisitivo da família e dos seus hábitos e costumes. Durante esse momento foi possível observar diferenças locais nos hábitos alimentares das crianças bem como na sua relação com o alimento.

$\mathrm{Na}$ EMPM, localizada no bairro de Tabatinga, área rural do município de Camaragibe, a grande maioria das crianças, de idades entre 08 a 12 anos, não só conhecia uma grande variedade de vegetais, como os consumia frequentemente e muitos os tinham plantados em suas casas. Essa escola possui uma horta mantida pelos funcionários com a ajuda dos alunos. Assim, eles adquirem a vivência com esses alimentos na escola e fora dela. Observamos nesse caso que o fator cultural tem mais peso do que 0 fator econômico. Apesar de viverem em uma comunidade de menor poder aquisitivo, os hábitos familiares de consumo permitem que essas crianças tenham uma alimentação mais saudável. Devemos levar em conta também o fato de estarem localizadas em uma área rural, onde há maior possibilidade de plantio de árvores frutíferas e hortaliças nos próprios quintais de suas casas, como fizeram na escola.

$\mathrm{Na}$ EEPBCM, localizado no bairro de Barra de Jangada, Jaboatão dos Guararapes, os próprios alunos mantêm uma horta no local. Essa horta faz parte do projeto da disciplina de Biologia. $O$ fato deles já terem o contato direto com a horta e com os alimentos cultivados influencia diretamente na sua alimentação. Por serem alunos já do Ensino Médio, já possuem também uma maior consciência sobre a importância de hábitos alimentares saudáveis.

Já na EEPIS, os vegetais não foram tão citados como parte do cardápio da maioria dos alunos. Esta é uma escola urbana, situada em um bairro bastante populoso do município de Recife, com poucas áreas verdes, sendo a praia o único contato que os moradores têm com o ambiente natural. 
O próprio espaço escolar reduzido impede a manutenção de áreas abertas e verdes, como jardins, predominando assim o cinza, o concreto.

A comparação entre os hábitos alimentares dos alunos de cada escola e seu espaço escolar nos leva à conclusão de que a presença da horta nas escolas tem um peso importante na alimentação dos alunos, que por sua vez vão influenciar as escolhas dos seus familiares por levarem para casa os ensinamentos trabalhados na escola.

Ao fim desse momento, solicitamos aos alunos que armazenassem restos de alimentos (oriundos de casa ou da própria escola) para serem utilizados no encontro seguinte, onde construiríamos os sistemas de compostagem.

\section{Construção do sistema de compostagem}

Para a construção do sistema de compostagem, utilizamos baldes de 15L, brita, pedras ou cascalhos, terra, restos de alimentos e folhas secas. Todo o sistema foi montado com os alunos, e durante essa montagem fomos explicando todo o processo de decomposição que ocorre dentro do sistema.

Primeiramente fizemos um furo na lateral do balde com o auxílio de um ferro de solda para a instalação de uma torneira. Esse balde (branco, como mostra a Figura 3 abaixo) constitui a base do sistema onde será coletado o chorume. Na tampa do balde, fizemos um corte no seu perímetro interno deixando apenas um aro para sustentar o segundo balde a ser encaixado sobre aquele. Já o segundo balde (laranja) teve toda a sua base furada com o auxílio de um ferro de solda, bem como suas laterais próximo ao topo (Figura 3).

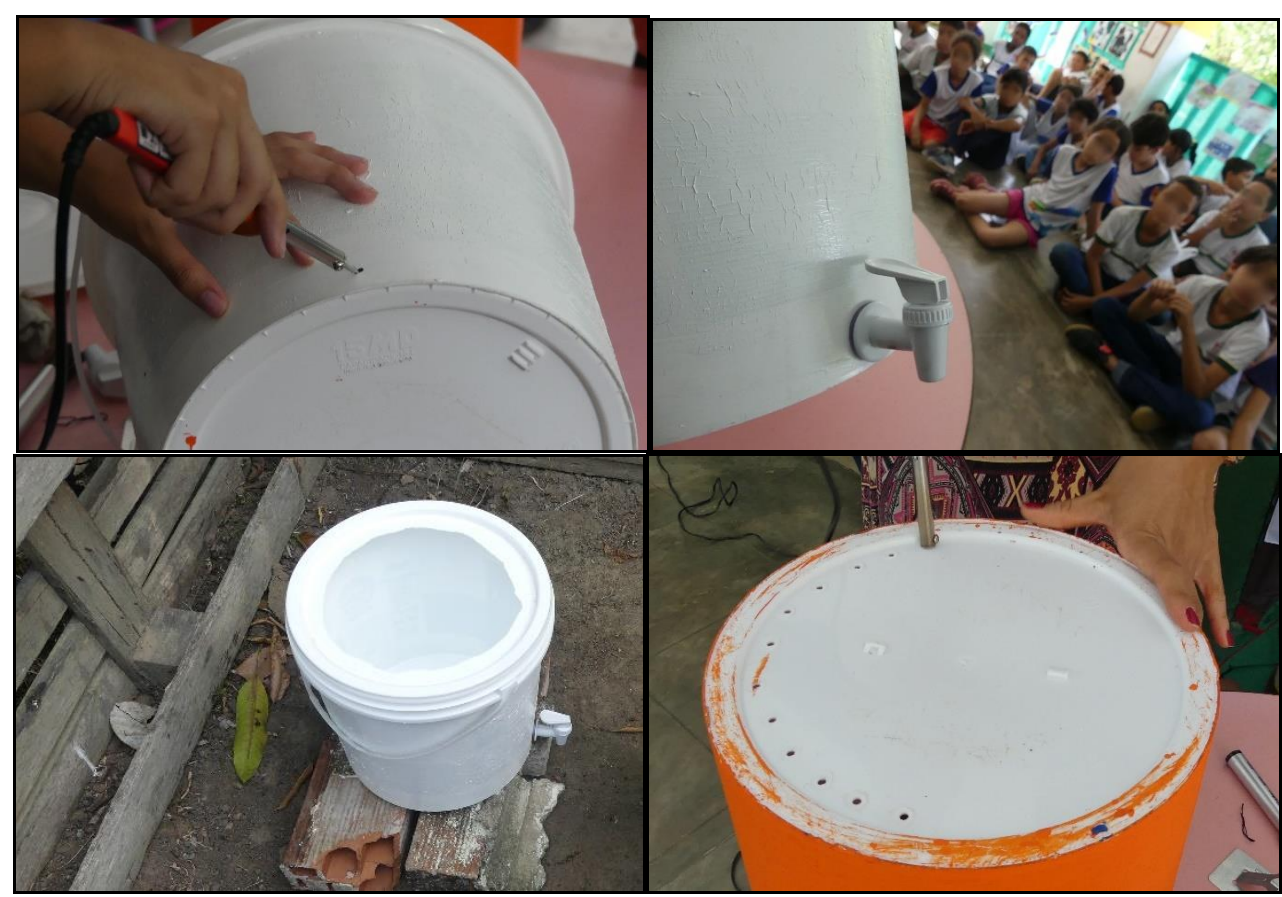

Figura 3: Construção do sistema de compostagem.

Fonte: os autores. 
Esse segundo balde (laranja), uma vez encaixado no primeiro foi preenchido por uma camada de brita, seguido de uma camada de terra, uma camada com os resíduos alimentares, mais uma camada de terra e para finalizar, uma camada de folhas secas (Figura 4).

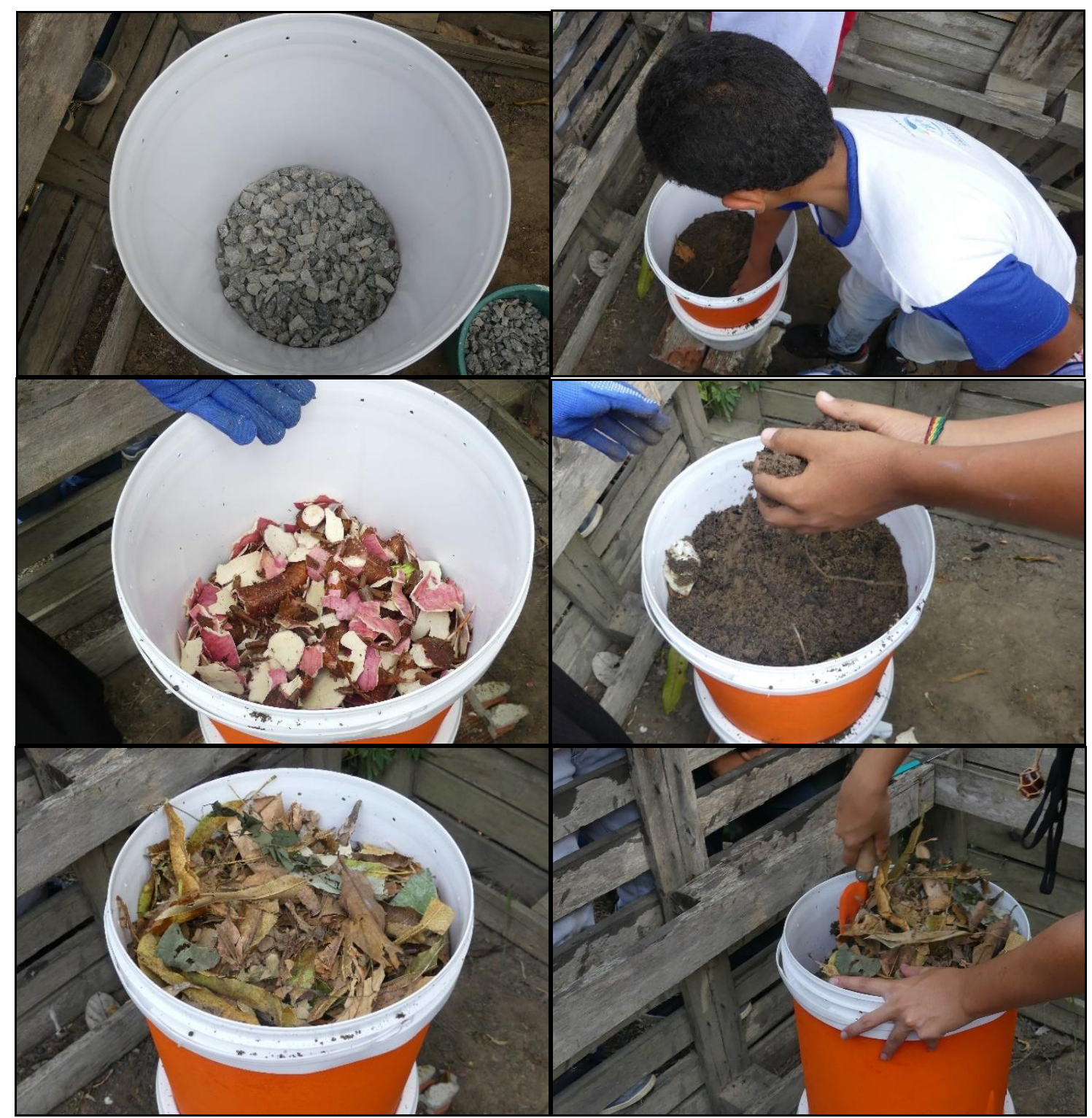

Figura 4: Montagem do sistema de compostagem.

Fonte: os autores.

O processo de decomposição ocorre dentro deste segundo balde, e o resíduo líquido deste processo, denominado chorume, passa pelo filtro criado pelas britas na sua base e é recolhido no primeiro balde. No início do processo de decomposição, denominada fase de aquecimento ou fermentação, há a quebra da parte fibrosa, mais complexa da matéria orgânica. Durante essa 
fase, os micro-organismos (bactérias e fungos) presentes no solo adicionado ao sistema apresentam suas máximas taxas metabólicas, o que causa 0 aquecimento do sistema. As taxas máximas de fermentação acontecem a temperaturas entre $60-70^{\circ} \mathrm{C}$, acima disso os micro-organismos começam a morrer e o processo de decomposição pode cessar. Essa fase se inicia geralmente 4-5 dias após a montagem do sistema e dura aproximadamente 15 dias.

A fase seguinte, denominada fase de resfriamento, é mais longa, podendo durar alguns meses. Nessa fase, o processo de decomposição não gera mais tanta energia e a temperatura cai para $30^{\circ} \mathrm{C}$ aproximadamente. Essa é a fase em que os micro-organismos convertem os componentes orgânicos em húmus. A terceira e última fase, denominada maturação, é um período de estabilização, onde há a diminuição da atividade microbiana, juntamente com as quedas gradativas de temperatura que se aproxima à temperatura ambiente. Essa fase dura indefinidamente, uma vez que o processo de decomposição prossegue a taxas muito baixas. $\mathrm{O}$ composto estará pronto para ser adicionado ao solo quando estiver apresentando a coloração preta/marrom de solo orgânico (INCKEL et al., 2005).

Esse sistema de compostagem também pode ser montado em escala menor, e sendo assim, realizamos oficinas com os alunos para confecção do sistema reduzido de compostagem utilizando garrafas de polietileno tereftalato (PET). A montagem desse sistema segue as mesmas etapas do sistema original, porém em menor escala (Figura 5).

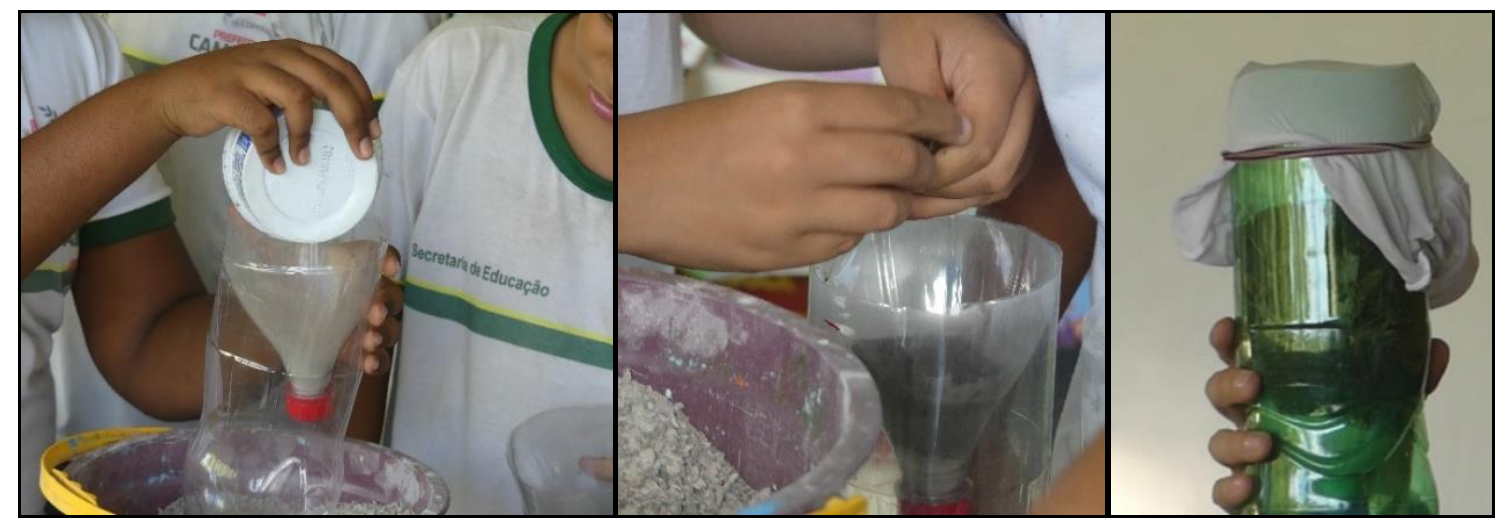

Figura 5: Construção e montagem do sistema de compostagem em garrafa PET.

Fonte: os autores.

Primeiro cortamos a garrafa ao meio e fizemos vários furos na tampa. A metade superior da garrafa é então inserida emborcada na metade inferior. A composteira será montada na metade emborcada enquanto a base coletará o chorume que passará pela tampa furada. A montagem do sistema segue então o padrão descrito acima: brita + terra + resíduos orgânicos + terra + folhas secas. Devido ao menor tamanho do sistema, é ideal utilizar brita de menor tamanho. Para vedar o sistema, mas permitir a passagem de ar, uma rede de malha fina como tule, mosquiteiro ou meia fina presos com um elástico 
impedem a proliferação de insetos no sistema. Esse sistema é ideal para espaços menores, como apartamentos.

As três escolas participantes variaram tanto em termos de composição etária dos alunos, quanto de localização e espaço físico, e mesmo nas escolas onde já havia hortas estabelecidas (EEPBCM e EMPM), o sistema de compostagem foi recebido com curiosidade e entusiasmo tanto pelos alunos quanto pelos professores e funcionários. Na EEPBCM e na EMPM realizamos a montagem da composteira tradicional para o espaço escolar e do modelo compacto, em garrafas PET, para que eles possam reproduzir em casa. $\mathrm{Na}$ EEPIS, em função do espaço restrito, realizamos apenas a montagem do sistema compacto.

Durante a montagem do sistema de compostagem foi possível descrever todo o processo de decomposição do material orgânico e como a temperatura, a umidade e a qualidade dos resíduos alimentares utilizados interferem nesse processo. Na composteira só devem entrar resíduos vegetais, pois resíduos de origem animal apresentam processo de decomposição mais lento. Além disso, não devem entrar resíduos que tenham tido contato com óleos ou gorduras vegetais ou animais, pois a gordura interfere no metabolismo microbiano, retardando o processo de decomposição. Sendo assim, o ideal é que sejam utilizados apenas os resíduos crus como cascas e sementes, ou os cozidos apenas em água. A temperatura e a umidade do ambiente interferem diretamente na velocidade da decomposição, de modo que a estação do ano em que se inicia a composteira poderá influenciar também na duração do processo.

O acompanhamento da composteira pelos alunos ao longo do tempo permite a vivência in situ desse processo, atuando assim com um laboratório natural. Independente da faixa etária trabalhada, é possível retomar os conceitos de química, física e biologia trabalhados em sala de aula e trabalhálos na prática com essa atividade. Para os professores, essa foi também uma ótima oportunidade de reciclar seus conhecimentos e introduzir uma nova possibilidade de atividade prática pra as futuras turmas.

Como todos tiveram a oportunidade de participar do processo desde 0 início, foi possível uma maior atenção e aprendizado da técnica. E por ser um sistema de fácil aquisição e montagem, utilizando materiais simples e de baixo custo, e dada a atenção desprendida pelos alunos, acreditamos que eles conseguirão refazê-los em suas residências junto aos seus familiares.

\section{Implantação e manutenção das hortas}

A implantação da horta se deu de formas diferentes a cada escola trabalhada dependendo da estrutura local. Enquanto a EEPBCM e a EMPM já possuíam uma horta organizada no espaço escolar, razão pela qual foram escolhidas para esse projeto, a EEPIS não possuía nenhuma estrutura ou espaço, e ali implantamos um sistema de horta vertical. Para tal, utilizamos 
garrafas PET, terra, mudas e arames. As garrafas foram cortadas no plano horizontal, e furadas nas laterais para a passagem do arame que sustentará a horta vertical, como mostra a Figura 6. Em seguida estas foram preenchidas com terra e inseridas as mudas. Utilizamos nessa atividade mudas de ervas aromáticas como a cebolinha (Allium schoenoprasum, família Amaryllidaceae), o manjericão roxo (Ocium Basilicum Varo Crispum, família Lamiaceae), o alecrim (Rosmarinus officinalis, família Lamiaceae), a hortelã (Mentha spicata, família Lamiaceae), e a pimenta (Capsicum, família Solanaceae) e mudas de plantas ornamentais como a Gazania (família Asteraceae) e a "onze horas" (Portulaca grandiflora, família Portulacaceae). Todo o processo foi realizado em conjunto com os alunos, que foram divididos em grupos para facilitar a execução e todos poderem participar. Ao final da montagem, a horta foi fixada próximo ao refeitório da escola, local de convivência de toda a comunidade escolar.

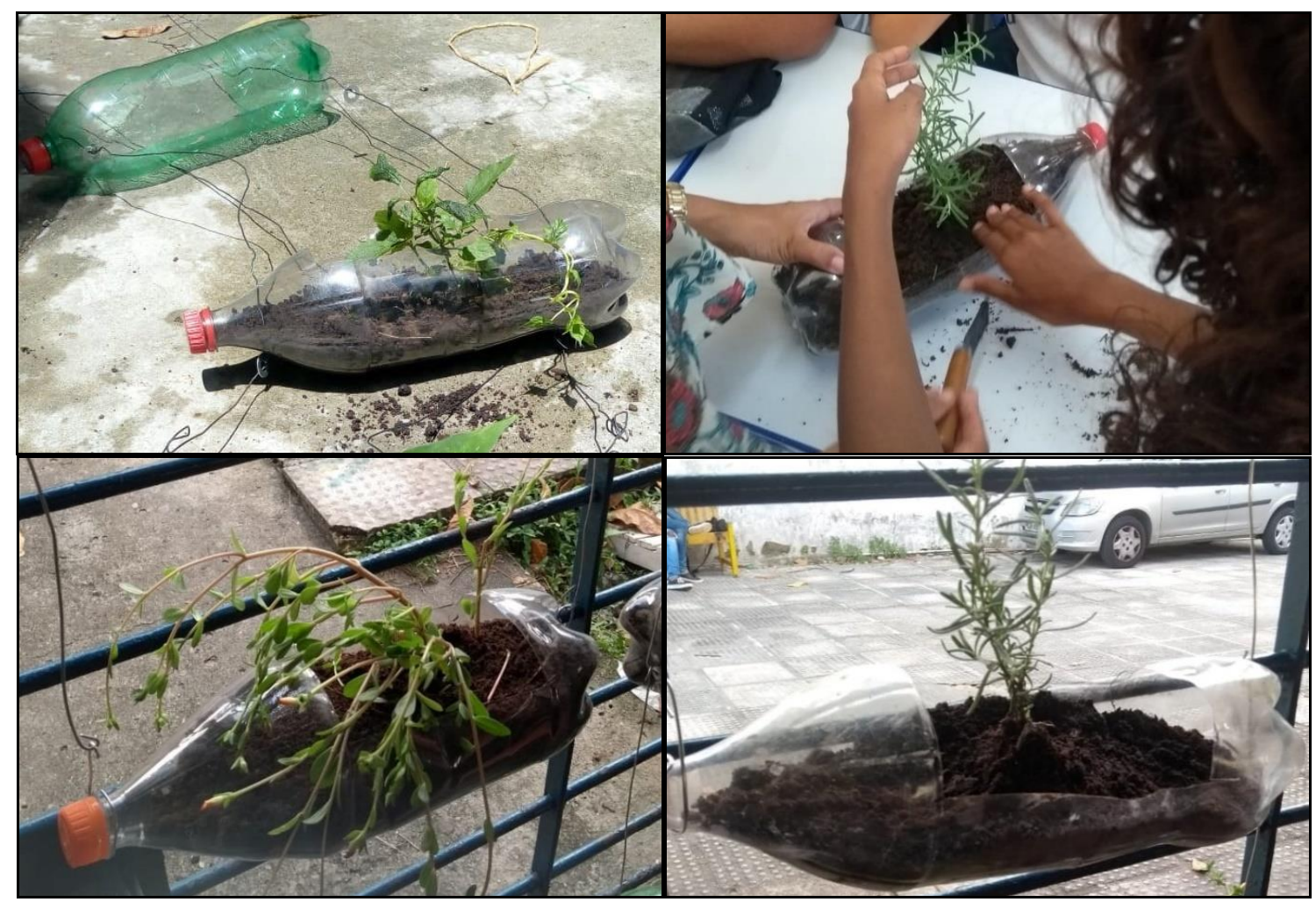

Figura 6: Montagem da horta vertical.

Fonte: os autores.

$\mathrm{Na}$ EEPBCM, os alunos do Ensino Médio mantem uma horta comunitária, como parte dos requisitos da disciplina de Biologia (Figura 7). Após a construção do sistema de compostagem com os alunos dessa escola, aproveitamos para conversar sobre a importância das plantas que estão sendo cultivadas. Utilizando latas de alumínio, confeccionamos placas para a identificação das espécies plantadas, onde os próprios alunos preenchiam com o nome comum, o nome científico, e a família botânica de cada espécie. 


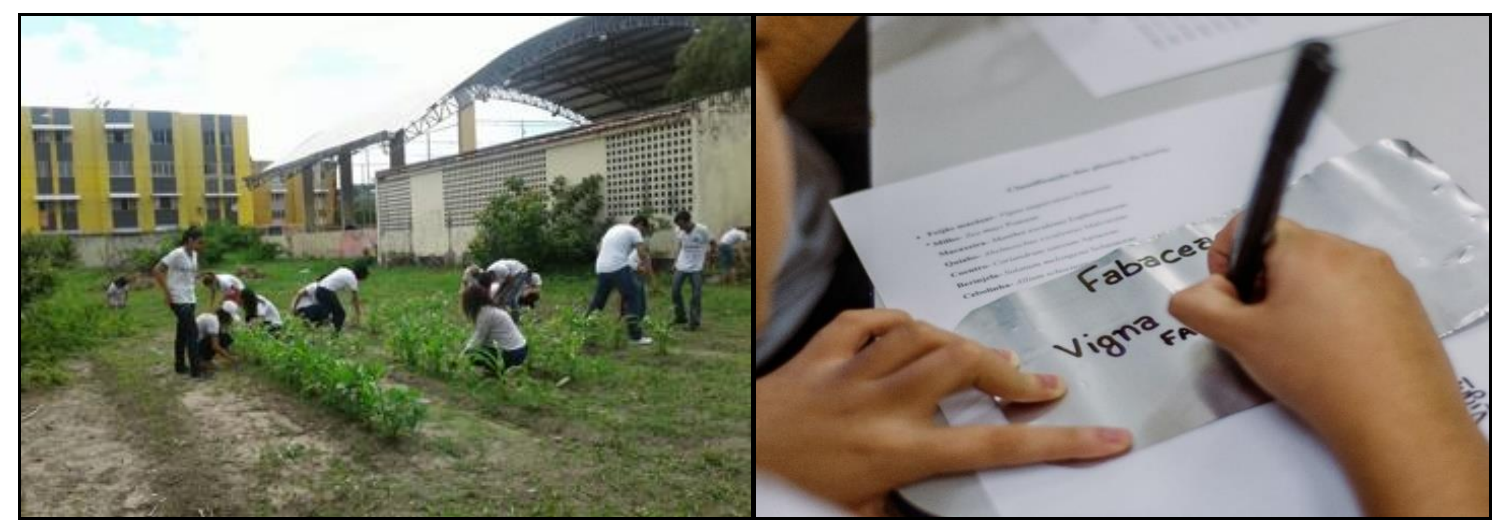

Figura 7: Horta comunitária mantida pelos alunos do Ensino Médio na EEPBCM (esquerda); montagem das placas de identificação das espécies da horta (direita).

Fonte: os autores.

Na EMPM a horta é mantida por um funcionário da escola e os alunos do Ensino Fundamental I participam da manutenção da horta como atividade escolar (Figura 8). Assim, todo o processo de irrigação, semeadura ou plantio de mudas e colheita é realizado com o auxílio dos alunos. O adubo gerado pela composteira que eles mesmos ajudaram a construir e manter está sendo utilizado diretamente na horta, o que estreita ainda mais a relação das crianças com todo o processo.

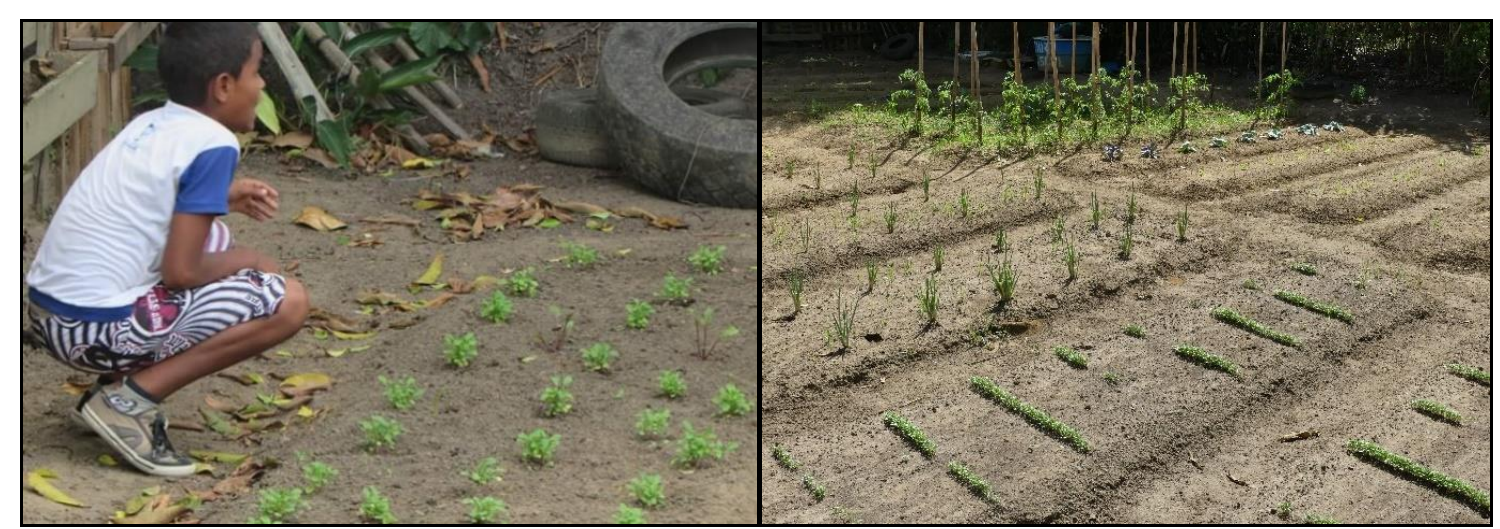

Figura 8: Horta comunitária mantida pelos funcionários auxiliados pelos alunos do Ensino Fundamental I na EMPM.

Fonte: os autores.

Durante o processo de manutenção das hortas horizontais existentes e implementação da horta vertical, trabalhamos com os alunos a identificação das diferentes espécies de plantas cultivadas, seus nomes comuns e científicos, o processo de aquisição de água e nutrientes pelas raízes, a distribuição destes pela planta, a fotossíntese e realocação dos fotossintatos, os cuidados que devem ser tomados desde o início do plantio, como escolha do local, irrigação e utilização de adubo, as diferentes necessidades fisiológicas 
de cada espécie, tanto de água e nutrientes quanto de iluminação, além de reforçarmos a importância da alimentação saudável e orgânica. O fato de não haver espaço na EEPIS para a implantação da horta horizontal não afetou em absoluto a atenção e interesse dos estudantes, o que nos mostra que o espaço ou infraestrutura disponível na escola não configura nenhum impedimento para a realização e apreciação dessa atividade.

Uma vez estabelecidos os sistemas de compostagem e as hortas nas escolas, a avaliação da produção dos sistemas e a manutenção das hortas nas escolas vem ocorrendo em um processo contínuo através de visitas periódicas às escolas e contato com os coordenadores locais. Esse contato é de fundamental importância para garantirmos a continuidade do trabalho.

\section{Considerações finais}

Os resultados alcançados com esse projeto extrapolaram nossas expectativas. Nosso objetivo de promover uma discussão sobre a importância da alimentação saudável, do consumo de alimentos cultivados de forma orgânica e livre de agrotóxicos e da redução de resíduos, tanto para a saúde humana quanto para a saúde ambiental foi plenamente atingido. As comunidades das escolas onde desenvolvemos o projeto foram amplamente receptivas e disponíveis, o que facilitou imensamente a interação, a execução do projeto e o aprendizado proposto. Mesmo após a finalização do projeto, seguimos em contato com os diretores das escolas, monitorando a utilização das composteiras e a manutenção das hortas e prestando toda a assessoria necessária para que os frutos desse projeto prevaleçam, tanto na vida escolar quanto no dia-a-dia das famílias beneficiadas através dos alunos e funcionários das escolas. Esperamos que ao compartilharmos essas experiências através desse artigo possamos influenciar mais educadores a desenvolver tais atividades em escolas, comunidades, associações de moradores, e assim continuarmos espalhando essas sementes.

\section{Agradecimentos}

Somos profundamente gratos aos professores, diretores, alunos e seus responsáveis da Escola Estadual Professora Inalda Spinelli, Escola Estadual Professor Benedito Cunha Melo e Escola Municipal Padre Miguel pelo acolhimento, participação e disponibilidade. As atividades descritas nesse artigo fazem parte do Projeto de Extensão intitulado "Horta na escola: sustentabilidade e alimentação saudável", coordenado pela professora Mariana Guenther, desenvolvido pelo Núcleo de Pesquisas em Educação Ambiental e Cientifica (NUPEAC) e financiado pela Pro Reitoria de Extensão e Cultura da Universidade de Pernambuco (Edital PROEC 01/2018). 


\section{Referências}

ALBERGONI, L.; PELAEZ, V. Da Revolução Verde à agrobiotecnologia: ruptura ou continuidade de paradigmas? Revista de Economia, v. 33, n. 1, p. 31-53, 2007.

ANDRADES, T.; GANIMI, R. Revolução verde e a apropriação capitalista. CES Revista, v. 21, p. 43-56, 2007.

ASTRUP, A. et al. Nutrition transition and its relationship to the development of obesity and related chronic diseases. Obesity Reviews, v. 9, n. s1, p. 48-52, 2008.

BANCO do BRASIL, DIRETORIA de AGRONEGÓCIOS. Evolução histórica do crédito rural. Revista de Política Agrícola, v. 13, n. 4, 2004.

BARREIRA, L.; PHILIPPI Jr, A.; RODRIGUES, M. Usinas de compostagem do Estado de São Paulo: qualidade dos compostos e processos de produção. Engenharia Sanitária e Ambiental, v. 11, n. 4, p. 385-393, 2006.

BECK-FRIIS, B. et al. Formation and emission of $\mathrm{N}_{2} \mathrm{O}$ and $\mathrm{CH}_{4}$ from compost heaps of organic household wastes. Environmental Monitoring and Assessment, v. 62, n. 3, p. 317-331, 2000.

BELIK, W.; CUNHA, A.; COSTA, L. Crise dos alimentos e estratégias para a redução do desperdício no contexto de uma política de segurança alimentar e nutricional no Brasil. Planejamento e políticas públicas, v. 38, p. 107-132, 2012.

BULL, D.; HATHAWAY, D. Pragas e Venenos: agrotóxicos no Brasil e no Terceiro Mundo. Petrópolis: Vozes/OXFAM/FASE, 1986.

CANUTO, J. C. Sistemas agroflorestais: experiências e reflexões. Brasília: Embrapa, 2017.

CORRÊA, R. DA S. et al. Padrões alimentares de escolares: existem diferenças entre crianças e adolescentes? Ciência \& Saúde Coletiva, v. 22, n. 2, p. 553-562, 2017.

COSTA, E. DE Q.; RIBEIRO, V. M. B.; RIBEIRO, E. C. DE O. Programa de alimentação escolar: espaço de aprendizagem e produção de conhecimento. Revista de Nutrição, v. 14, n. 3, p. 225-229, 2001.

EGGERTH, L.L. et al. Marketing of composts. Waste Management Series, v. 8, p. 325-355, 2007.

FUNGWE T. et al. The quality of children's diets in 2003-04 as measured by the healthy eating index-2005. Nutrition Insight 43 - Center for Nutrition Policy and Promotion, U.S. Department of Agriculture, 2009.

FÜRSTENAU, V. A política de crédito rural na economia brasileira pós 1960 . Ensaios FEE, v. 8, n. 1, p. 139-154, 1987. 
GOLLEY, R. K.; HENDRIE, G. A.; MC NAUGHTON, S. A. Scores on the dietary guideline index for children and adolescents are associated with nutrient intake and socio-economic position but not adiposity. The Journal of Nutrition, v. 141, n. 7, p. 1340-1347, 2011.

INCKEL, M. et al. The preparation and use of compost. 7th Ed. Wageningen: Agromisa Foundation, 2005.

IBGE - INSTITUTO BRASILEIRO DE GEOGRAFIA E ESTATÍSTICA. Pesquisa de Orçamentos Familiares 2008-2009. Rio de Janeiro, 2010.

KIEHL, E. J. Fertilizantes Orgânicos. São Paulo: Agronômica Ceres Ltda., 1985.

LEMOS, A. G.; BOTELHO, R. B.; AKUTSU, R. DE C. C. Determinação do fator de correção das hortaliças folhosas comercializadas em Brasília. Horticultura Brasileira, v. 29, n. 2, p. 231-236, 2011.

LONDRES, F. 2011. Agrotóxicos no Brasil: um guia para ação em defesa da vida. Rio de Janeiro: AS-PTA - Assessoria e Serviços a Projetos em Agricultura Alternativa, 2011.

LOU, X. F.; NAIR, J. The impact of landfilling and composting on greenhouse gas emissions - a review. Bioresource Technology, v. 100, n. 16, p. 37923798, 2009.

LUNDGREN, B. O.; RAINTREE, J. B. Sustained agroforestry. In: NESTEL, B. (Ed.) Agricultural research for development: potentials and challenges in Asia. The Hague, The Netherlands: ISNAR, p. 37-49, 1982.

MALACHIAS M.V.B. et al. 7th Brazilian Guideline of arterial hypertension. Arquivos Brasileiros de Cardiologia. v. 107, n. 3, 2016.

MARCHETTO A.M.P. et al. Avaliação das partes desperdiçadas de alimentos no setor hortifruti visando seu reaproveitamento. Simbio-Logias, v. 1, p. 1-14, 2008.

MIKKILÄ, V. et al. Consistent dietary patterns identified from childhood to adulthood: the cardiovascular risk in young Finns study. British Journal of Nutrition, v. 93, n. 6, p. 923-931, 2005.

MOREIRA, R.J. Críticas ambientalistas à Revolução Verde. Estudos Sociedade e Agricultura, v. 8, n. 2, p. 39-52, 2000.

NCD Risk Factor Collaboration (NCD-RisC). Worldwide trends in body-mass index, underweight, overweight, and obesity from 1975 to 2016: a pooled analysis of 2416 population-based measurement studies in 128.9 million children, adolescents, and adults. The Lancet, v. 390, n. 10113, p. 2627-2642, 2017.

NELLEMANN, C. et al. The environmental food crisis: the environment's role in averting future food crises. A UNEP rapid response assessment. Arendal: United Nations Environment Programme, GRID, 2009. 
NEUGEBAUER, M.; SOŁOWIEJ, P. The use of green waste to overcome the difficulty in small-scale composting of organic household waste. Journal of Cleaner Production, v. 156, p. 865-875, 2017.

NEVES, M.C.P.; DUARTE, R.L.; PEIXOTO, R.T.G. Riscos associados ao uso de fertilizantes. In: PAS CAMPO (Ed.) Elementos de apoio para as boas práticas agrícolas e o sistema APPCC/PAS Campo. $2^{\mathrm{a}}$ ed. Brasília: Embrapa. p. 93-103, 2006.

NORTHSTONE, K. et al. Longitudinal comparisons of dietary patterns derived by cluster analysis in 7- to 13-year-old children. British Journal of Nutrition, v. 109, n. 11, p. 2050-2058, 2012.

OLIVEIRA, F.N.S; LIMA, H.J.M; CAJAZEIRA, J.P. Uso da compostagem em sistemas agrícolas orgânicos. Fortaleza: Embrapa Agroindústria Tropical, 2004.

PERES, F.; MOREIRA, J.C. É veneno ou é remédio? Agrotóxicos, saúde e ambiente. Rio de Janeiro: Editora Fiocruz, 2003.

POPKIN, B. M.; ADAIR, L. S.; NG, S. W. Global nutrition transition and the pandemic of obesity in developing countries. Nutrition Reviews, v. 70, n. 1, p. 3-21, 2012.

PORTO, M. F.; SOARES, W. L. Modelo de desenvolvimento, agrotóxicos e saúde: um panorama da realidade agrícola brasileira e propostas para uma agenda de pesquisa inovadora. Revista Brasileira de Saúde Ocupacional, v. 37, n. 125, p. 17-50, 2012.

RAZZA, F. et al. The role of compost in bio-waste management and circular economy. In: BENETTO, E.; GERICKE, K.; GUITON, M. (Eds.) Designing sustainable technologies, products and policies. Cham: Springer, p. 133143, 2018.

ROSSI, A.; MOREIRA, E. A. M.; RAUEN, M. S. Determinantes do comportamento alimentar: uma revisão com enfoque na família. Revista de Nutrição, v. 21, n. 6, p. 739-748, 2008.

RUGGIERI, L. et al. Recovery of organic wastes in the Spanish wine industry. Technical, economic and environmental analyses of the composting process. Journal of Cleaner Production, v. 17, n. 9, p. 830-838, 2009.

SMÅRS, S. et al. Improvement of the composting time for household waste during an initial low pH phase by mesophilic temperature control. Bioresource Technology, v. 84, n. 3, p. 237-241, set. 2002.

TAIWO, A. M. Composting as a sustainable waste management technique in developing countries. Journal of Environmental Science and Technology, v. 4, n. 2, p. 93-102, 2011. 